\title{
VOYEURISM AND SCOPOPHILIA
}

\author{
TUDOR POPA ${ }^{1}$, CRISTIAN DELCEA $^{1,2, *}$ \\ 'Iuliu Hațieganu University of Medicine and Pharmacy, Cluj-Napoca, Romania \\ ${ }^{2}$ Sexology Institute of Romania, Cluj-Napoca, Romania
}

\begin{abstract}
Formerly known as Voyeurism in DSM-IV, this disorder refers to (for over a period of at least 6 months) having recurrent, intense sexually arousing fantasies, sexual urges, or behaviors involving the act of observing an unsuspecting person who is naked, in the process of disrobing, or engaging in sexual activity. The person being considered for this disorder, in some way, has acted on these urges towards an nonconsenting person or the sexual fantasies/urges cause clinically significant distress or impairment in social, occupational, or other important areas of functioning.
\end{abstract}

Keywords: voyeurism, disorder, sexual arousal, fantasies.

\section{INTRODUCTION}

Voyeurism - involves the act of looking at individuals who do not realize that they are, as a rule, strangers, who are naked, in the process of stripping or engaged in sexual activity.

\section{Theoretical approaches}

Voyeurism, sometimes called scopophilia, is the observation of the sexual activity of other people repeatedly, as a preferred means of obtaining sexual arousal. The act of peeping is directed at foreign persons, who do not know they are watched, who are in the bare pill (nudes), or are stripped of or engaged in a sexual act, without being followed by the attempt to maintain sexual relations. with these. Voyeurism is a disorder of heterosexual individuals who have inappropriate sexual activity. Although they hide themselves so they cannot be seen, they are often caught on the fact or by the victim or more often by passersby. Orgasm, following sexual arousal through watching, occurs through masturbation during voyeuristic activity or later, when he remembers what he saw.

Voyeurism is apparently more common in men, but its prevalence is not known. The onset seems to occur before the age of 15, in adolescence, as an expression of sexual curiosity being replaced by normal sexual intercourse. With the passage of time, this activity can be chronicled, continuing to shoot with the eye, even if shy, especially in places where people walk naked (eg beaches with nudists). A new variant of voyeurism is listening to erotic conversations, such as sex on the phone.

The object of voyeurism is to observe unsuspecting individuals who are naked, in the process of undressing or engaging in sexual acts. The person being observed is usually a stranger to the observer. The act of looking or peeping is undertaken for the purpose of achieving sexual excitement. The observer generally does not seek to have sexual contact or activity with the person being observed. If orgasm is sought, it is usually achieved through masturbation. This may occur during the act of

*Corresponding author: 160 Plevnei Street, Cluj-Napoca, 400000, Romania, Phone/Fax: 0264 550247, email cristian.delcea.cj@gmail.com 
observation or later, relying on the memory of the act that was observed. Frequently, a voyeur may have a fantasy of engaging in sexual activity with the person being observed. In reality, this fantasy is rarely consummated.

A number of states have statutes that render voyeurism a crime. Such statutes vary widely regarding definitions of voyeurism. Most states specifically prohibit anyone from photographing or videotaping another person, without consent, while observing that person in the privacy of his home or some other private place. There is no scientific consensus concerning the basis for voyeurism. Most experts attribute the behavior to an initially random or accidental observation of an unsuspecting person who is naked, in the process of disrobing, or engaging in sexual activity. Successive repetitions of the act tend to reinforce and perpetuate voyeuristic behavior.

The act of voyeurism is the observation of an unsuspecting person who is naked, in the process of disrobing, or engaging in sexual activity that provides sexual arousal.

To be clinically diagnosed, the symptoms must include the following elements:

- recurrent, intense or sexually arousing fantasies, sexual urges, or behaviors

- fantasies, urges, or behaviors that cause significant distress to an individual or are disruptive of his or her daily functioning.

According to the mental health professional's handbook, Diagnostic and Statistical Manual of Mental Disorders, two criteria are required to make a diagnosis of voyeurism:

- Over a period of at least six months, an individual must have recurrent, intense, sexually arousing fantasies, sexual urges, or behaviors that involve the act of observing an unsuspecting person who is naked, in the process of disrobing, or engaging in sexual activity.

- The fantasies, sexual urges, or behaviors must cause clinically significant distress or impairment in social, occupational, or other important areas of functioning. In order for a condition to be labeled "voyeurism," the fantasies, urges, or behaviors to watch other persons must cause significant distress in the individual or be disruptive to his or her daily functioning.

\section{CONCLUSIONS}

For treatment to be successful, a voyeur must want to modify existing behavior patterns. This initial step is difficult for most voyeurs to admit and then take. Most must be compelled to accept treatment. This may often be the result of a court order. Behavioral therapy is commonly used to try to treat voyeurism.

The voyeur must learn to control the impulse to watch non-consenting victims, and just as important to acquire more acceptable means of sexual gratification. Outcomes of behavioral therapy are not known. There are no direct drug treatments for voyeurism.

Voyeurism is a criminal act in many jurisdictions. It is usually classified as a misdemeanor. As a result, legal penalties are often minor.

The possibility of exposure and embarrassment may deter some voyeurs. It is also not easy to prosecute voyeurs as an attempt to watch is difficult to prove. In their defense statements, they usually claim that the observation was accidental.

Most experts agree that providing guidance regarding behavior that is culturally acceptable will prevent the development of a paraphilia such as voyeurism.

The origin of some instances of voyeurism may be accidental observation with subsequent sexual gratification. There is no way to predict when such an event and association will occur. Members of society at large can reduce the incidence of voyeurism by drawing curtains, dropping blinds or closing window curtains.

Reducing opportunities for voyeurism may reduce the practice.

The prognosis for eliminating voyeurism is poor because most voyeurs have no desire to change their behavior pattern.

Since voyeurism involves non-consenting partners and is against the law in many jurisdictions, the possibility of embarrassment may deter some individuals. 
Funding Sources: This research did not receive any specific grant from funding agencies in the public, commercial, or not-for-profit sectors.

\section{REFERENCES}

1. Sadock BJ, Sadock VA. Kaplan and Sadock's Synopsis of Psychiatry: Behavioral Sciences and Clinical Psychiatry, Ninth Edition. Philadelphia: Lippincott Williams \& Wilkins; 2003. [Google Scholar]

2. Levine SB, Althof SE, editors. Handbook of Clinical Sexuality for Mental Health Professionals. New York: Brunner-Routledg; 2003. [Google Scholar]
3. Levine SB, editor. Sexual disorders. In: Tasman A, Kay J, Lieberman J. Psychiatry, Second Edition. Hoboken, NJ: Wley; 2003. [Google Scholar]

4. Levine SB. Reexploring the concept of sexual desire. J Sex Marital Ther 20022839-51 [PubMed] [Google Scholar]

5. Masters WH, Johnson VE. Boston: Little, Brown \& Co.; 1966. Human Sexual Response. [Google Scholar]

6. Bechtel S The practical encyclopedia of sex and health: From aphrodisiacs and hormones to potency, stress, vasectomy, and yeast infection. Emmaus (PA): Rodale; 1993. [Google Scholar] 